\title{
Public health programme and policy options for improving health equitably
}

\author{
${ }^{1} \mathrm{SJ}$ Haw, ${ }^{2} \mathrm{JW}$ Frank, ${ }^{3} \mathrm{H}$ Frost, ${ }^{4} \mathrm{RV}$ Geddes, ${ }^{5} \mathrm{CA}$ Jackson, ${ }^{6} \mathrm{~J}$ Mooney \\ ${ }^{1}$ Senior Scientific Advisor, Scottish Collaboration for Public Health Research \& Policy (SCPHRP), and Honorary Reader, Centre for Population \\ Health Sciences, University of Edinburgh; ' ${ }^{2}$ irector, SCPHRP, and Professor of Public Health Research \& Policy, Centre for Population Health \\ Sciences, University of Edinburgh; ${ }^{3-6}$ Career Development Fellow, SCPHRP, Edinburgh, UK
}

KEYWORDS Health inequalities, effective interventions, parenting, risk behaviours, obesity, aging

DECLARATION OF INTERESTS No conflict of interests declared.

\author{
Correspondence to JW Frank, \\ MRC Human Genetics Unit, \\ Western General Hospital, \\ Edinburgh EH4 2XU, UK
}

tel. +44 (0) I3। 332247 I ext. 2 I3I e-mail john.frank@hgu.mrc.ac.uk
Compared with other Western European countries, Scotland has the highest mortality rate and lowest life expectancy. Scotland is also characterised by marked inequalities, with men from the poorest communities dying 13 years earlier and experiencing seven more years in poor health than men from the most affluent communities.' Similarly, women from Scotland's poorest communities die nine years earlier and experience nine more years in poor health than women from the most affluent communities.' There has been little change in these markers of health inequalities over the past decade, in spite of a plethora of public health policies and programmes - which to date have largely focused on changing individual lifestyles rather than the broader social determinants of health. Indeed, there is substantial evidence that health inequalities in youth and younger adults have increased, initially in males and, more recently, in females, due to an increasing burden of ill health and death related to various forms of 'self-harm' such as alcohol and drug abuse, violence and suicide. ${ }^{2}$

In the coming years, Scotland is likely to face dramatic cuts in funding for the public sector and there will undoubtedly be some disinvestment in health, education and social services. This will require some tough decisions on the part of planners and policy makers. Prioritisation of investment will be essential if the adverse consequences of budget cuts are to be minimised. However, with a developing evidence base about effective public health interventions and programmes, we are now in a better position than ever to provide a rational basis for prioritising investment that is most likely to reduce the burden of disease in Scotland.

The evidence is now overwhelming that early life experience has a major impact on a wide range of health and social outcomes and is the root of many of the problems of the twenty-first century - addictions, mental health problems, obesity, under-achievement and coronary heart disease. ${ }^{3}$ However, the sensitive periods in brain development in the first five years of life that make young children particularly susceptible to adverse social and economic conditions, also make them amenable to early intervention. ${ }^{4,5}$ Furthermore, investment in interventions that promote good parenting and attachment and support the social and cognitive development of infants and toddlers have been shown to improve both short- and longer-term outcomes. ${ }^{3}$ In his strategic review of health inequalities in England, Marmot argues for proportionate universalism in which the scale and intensity of early intervention is proportionate to the level of disadvantage. ${ }^{6}$ Overall, this might amount to a commitment of $1 \%$ of gross domestic product, as recommended by UNICEF,' to develop an effective mix of policies and programmes in the public sector to support children's early development.

The Scottish Collaboration for Public Health Research and Policy was established in 2008, and an initial focus has been the identification of effective interventions addressing social determinants of priority Scottish health problems across the four life stages, presented in a series of structured reviews, soon to be available at www.scphrp.ac.uk. For the first life stage, Geddes and colleagues outline a mix of programmes for mothers and their young children in Scotland, which would build on and enhance existing early years work and have the potential to improve the life chances of children in a matter of a few years. ${ }^{8}$

The evidence base is less well developed for interventions in adolescence than for early life, but Jackson and colleagues have identified three multimodal programmes that are shown to be effective in reducing multiple risk behaviours. ${ }^{9}$ To date, most intervention programmes to promote health and well-being in adolescents in Scotland have focused on individual risk behaviours.

As regards working life, tackling obesity has been identified as a public health priority in Scotland. While a 
wide range of interventions show some promise, Mooney and colleagues fully concur with the recent UK Government Foresight report, Tackling obesities: future choices, ${ }^{10}$ in asserting the need for a comprehensive multicomponent approach that addresses the fundamental structural and economic drivers of the pandemic itself." They highlight the use of a validated framework to balance the strength of evidence against potential population impact, for a suite of potential policy interventions around restricting access to high-energy foods and removing barriers to more active living."

Finally, considering interventions in later life, Frost and colleagues conclude that, in spite of an extensive literature, there are large gaps in the evidence base and, where studies have been conducted, evidence on

\section{REFERENCES}

I Scottish Government Health Analytical Services Division. Longterm monitoring of health inequalities: headline indicators. Edinburgh Scottish Government; 2009. Available from: http://www.scotland. gov.uk/Publications/2009/09/25II22II/0

2 Leyland AH, Dundas R, McLoone $\mathrm{P}$ et al. Inequalities in mortality in Scotland 198I-200I. Glasgow: MRC Social and Public Health Sciences Unit; 2007. Available from: http://www.sphsu.mrc.ac.uk/ reports/OP016.pdf

3 Irwin L, Siddiqi A, Hertzman C. Early child development: a powerful equalizer.Vancouver: Human Early Learning Partnership; 2007.

4 McCain MN, Mustard JF. Reversing the real brain drain: early years study. Final report. Toronto: Publications Ontario; 1999.

5 Shonkoff JP, Phillips D, editors. From neurons to neighborhoods: the science of early childhood development. Washington, DC: National Academy Press; 2000.

6 Marmot M. Fair society, healthy lives. Strategic review of health inequalities in England post-2010. London: University College of London; 2010. Available from: http://www.marmotreview.org/ AssetLibrary/pdfs/Reports/FairSocietyHealthyLives.pdf

7 UNICEF. The childcare transition. Florence: UNICEF Innocenti Research Centre; 2008. Available from: http://www.unicef-irc.org/ publications/pdf/rc8_eng.pdf effectiveness is often conflicting due to unstandardised outcomes and poor experimental design. ${ }^{12}$ Nevertheless, there is some evidence for encouraging exercise, which can improve specific aspects of physical functioning in older people. ${ }^{12}$

To measure the impact of programmes that aim to address social determinants of health and reduce health inequalities, routine surveillance of population health status needs to move away from monitoring traditional indicators of mortality and hospitalisation towards the use of more sensitive measures of health and function that occur earlier in the life course, are amenable to change, reflect the future 'life chances' and health status and are strongly patterned by socio-economic position.

8 Geddes R, Haw S, Frank J. Early child development for health: an environmental scan with special reference to Scotland. Edinburgh: Scottish Collaboration for Public Health Research \& Policy; 2010. Available from: https://www.scphrp.ac.uk/node/l03

9 Jackson C, Haw S, Frank J. Adolescent and young adulthood health in Scotland: interventions that address multiple risk behaviours. Edinburgh: Scottish Collaboration for Public Health Research \& Policy; 20II. Available from: https://www.scphrp.ac.uk/node/I9|

10 Foresight. Tackling obesities: future choices. London:UK Government Office for Science; 2007. Available from: http://www.bis.gov.uk/ assets/bispartners/foresight/docs/obesity/l7.pdf

II Mooney J, Haw S, Frank J. Interventions to tackle the obesogenic environment - focusing on adults of working age in Scotland. Edinburgh: Scottish Collaboration for Public Health Research \& Policy; 2011. In press.

12 Frost $\mathrm{H}$, Haw S, Frank J. Interventions in primary care and community settings that prevent or delay disablement in older people. Edinburgh: Scottish Collaboration for Public Health Research \& Policy; 2011. In press.

\section{SENIOR FELLOWS' CLUB PRIZE}

This prize of $£ 200$ will be awarded to the first-named (or corresponding) author of an original research paper on a clinical topic, deemed by a panel of judges to be the best paper by a doctor-in-training (i.e. pre-consultant level) published in the The Journal of the Royal College of Physicians of Edinburgh in 2011.

Further details may be obtained from the Editorial Office, RCPE, 9 Queen Street, Edinburgh, EH2 IJQ, tel 0 I3। 2473652 or email editorial@rcpe.ac.uk. 